\title{
Pengaruh Direct Marketing Terhadap Keputusan Pembelian Kopi Arabika Malabar Mountain Coffee
}

Studi Kasus pada konsumen PT. Sinar Mayang Lestari

\author{
Regina Ramadani Yalanda ${ }^{1}$, Agriani Hermita Sadeli ${ }^{2}$ \\ Departemen Agribisnis, Fakultas Pertanian, Universitas Padjadjaran, Bandung \\ Email corresponding author : regina.yalanda@gmail.com
}

\begin{abstract}
ABSTRAK
Purpose of this study is to determine the effect of direct marketing on purchasing decisions of Arabica coffee Malabar Mountain Coffee. Coffee consumption in Indonesia in the past few years has increased by $8 \%$ per year. This is supported by the rapid growth of the coffee industry in several regions because there is more people are very fond of these drinks from coffee beans. The number of businesses engaged in similar businesses increase competitiveness between producers. One effort that needs to be done is to use the right marketing strategy to attract potential consumers. PT. Sinar Mayang Lestari is a coffee industry producer with the trademark Malabar Mountain Coffee. In dealing with competitors, companies use two forms of direct marketing, face to face selling and online marketing. Face to face selling is done through exhibition activities and coffee roadshows while online marketing through social media. Both forms of direct marketing serve as units of analysis in this study. This research is descriptive quantitative research using multiple linear regression where face to face selling and online marketing as independent variables and purchasing decisions as dependent variables. The sample selection in this study used a purposive technique with a sample of 100 respondents. Coclusion research results show that direct marketing together consisting of face to face selling and online marketing influences consumers in deciding to buy Arabica coffee Malabar Mountain Coffee.

Keywords: Buying Decision, Direct Marketing, Face to face Selling, Online Marketing.
\end{abstract}

\begin{abstract}
Tujuan dari penelitian ini adalah untuk menganalisis pengaruh direct marketing terhadap keputusan pembelian kopi arabika Malabar Mountain Coffee pelanggan PT. Sinar Mayang Lestari. Konsumsi kopi di Indonesia dalam kurun waktu beberapa tahun ini mengalami peningkatan sebesar 8\% pertahunnya. Hal ini didukung dengan pesatnya pertumbuhan usaha industri kopi dibeberapa daerah karena semakin banyak masyarakat yang sangat menyukai minuman yang berasal dari biji kopi ini. Banyaknya usaha yang bergerak di bisnis serupa menimbulkan tingginya persaingan yang kompetitif antar produsen. Salah satu upaya yang perlu dilakukan adalah menggunakan strategi pemasaran yang tepat untuk menarik minat beli konsumen potensial. PT. Sinar Mayang Lestari merupakan produsen industri kopi dengan merk dagang Malabar Mountain Coffee. Dalam menghadapi pesaing, perusahaan menggunakan dua bentuk direct marketing yaitu face to face selling dan online marketing. Face to face selling dilakukan melalui kegiatan exhibition dan juga roadshow coffee sedangkan online marketing melalui media sosial. Kedua bentuk direct marketing ini dijadikan sebagai unit analisis dalam penelitian ini. Penelitian ini adalah penelitian kuantitatif deskriptif menggunakan regresi linier berganda dimana face to face selling dan online marketing sebagai variabel bebas dan keputusan pembelian sebagai variabel terikat. Pemilihan sampel dalam penelitian ini menggunakan teknik purposive sampel dengan sampel sebanyak 100 responden. Hasil Penelitian memberikan kesimpulan bahwa direct marketing secara bersamasama yang terdiri dari face to face selling dan online marketing mempengaruhi konsumen dalam memutuskan untuk membeli kopi arabika Malabar Mountain Coffee.

Kata Kunci : Keputusan Pembelian, Direct Marketing , Face to face selling , Online Marketing
\end{abstract}

\section{PENDAHULUAN}

Pemasaran merupakan hal yang sangat penting dilakukan oleh sebuah perusahaan dalam menjalankan bisnis. Pemasaran yang baik harus dapat mengidentifikasi kebutuhan dan keinginan pelanggan sehingga akan memperoleh keuntungan bagi perusahaan (Rodriguez, Dixon, \& Peltier, 2014). Saat ini perkembangan industri kopi sudah sangat menjamur di Indonesia hal ini menyebabkan tingginya persaingan antar produsen dalam menarik minat beli konsumen hal ini dapat 
dilihat dari meningkatnya konsumsi domestik kopi Indonesia yang mengalami peningkatan sebesar 8\% pertahun menurut Asosiasi Eksportir dan Industri Kopi Indonesia (AEKI).

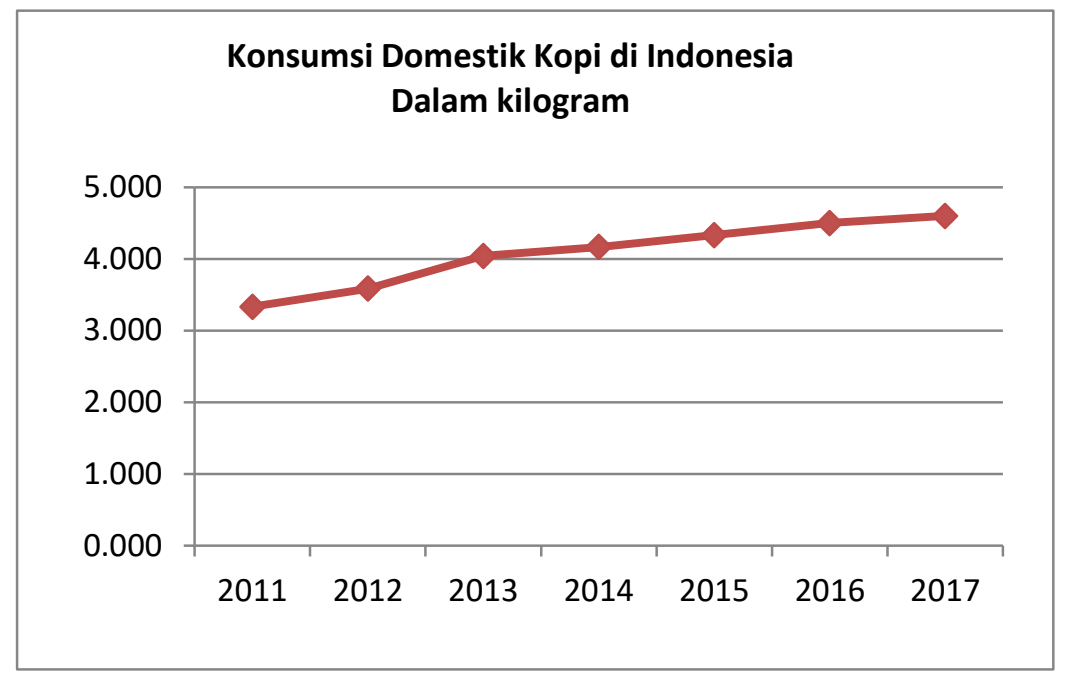

Gambar 1. Grafik Konsumsi Kopi Indonesia

Sumber : Asosiasi Eksportir dan Industri Kopi Indonesia (AEKI)

Oleh karena itu, perusahaan dituntut untuk memiliki keunggulan agar dapat bersaing dengan produsen kopi lainnya. Hal ini sesuai dengan teori pasar persaingan tidak sempurna monopilstik yaitu terdapat banyak produsen yang mengasilkan barang serupa, namun harus memiliki keunggulan tersendiri dalam beberapa aspek yang membedakan perusahaan satu dengan yang lainnya. Keunggulan tiap perusahaan ini terdiri dari beberapa faktor seperti, kualitas produk kopi yang dihasilkan, kualitas pelayanan yang diberikan, sistem pemasaran yang dilakukan, dan segmentasi pasar yang ditargetkan untuk menjual barang dan jasa yang dihasilkan. PT. Sinar Mayang Lestari merupakan salah satu produsen penghasil kopi jenis arabika dari sekian banyak perusahaan kopi yang menjual kopi arabika di Indonesia. Diperlukan strategi pemasaran yang tepat agar perusahaan dapat menarik keputusan pembelian konsumen. Strategi pemasaran yang dilakukan PT. Sinar Mayang Lestari adalah direct marketing yang merupakan bagian dari strategi pemasaran yang diarahkan untuk mempengaruhi perilaku konsumen terutama dalam pengambilan keputusan. Face to face selling dan online marketing merupakan dua bentuk strategi direct marketing yang dilakukan oleh PT. Sinar Mayang Lestari dalam memasarkan produk yang dijualnya.

Telah dilakukan beberapa penelitian mengenai Pengaruh direct marketing terhadap keputusan pembelian yang memberikan hasil bahwa direct marketing terbukti mempengaruhi konsumen dalam memutuskan untuk melakukan pembelian. Berdasarkan uraian latar belakang, penelitian ini dilakukan untuk mengetahui gambaran direct marketing dan pengaruh direct marketing terhadap keputusan pembelian kopi arabika Malabar Mountain Coffee PT. Sinar Mayang Lestari untuk melihat seberapa tepat penggunaan pemasaran langsung terhadap minat beli konsumen.

\section{TINJAUAN PUSTAKA} Direct Marketing

Direct marketing menurut (Ukaj \& Prof, 2016) adalah strategi pemasaran yang dilakukan untuk membangun komunikasi secara interaktif dengan konsumen agar perusahaan dapat membangun kedekatan dengan pelanggan untuk menimbulkan respon langsung. Respon yang dihasilkan pada proses dircet marketing bisa berupa inquiry, pembelian, atau bahkan dukungan. Menurut (Kotler, 2012) adalah suatu cara pemasar dalam mengkomunikasikan barang atau jasa yang dijual untuk mendorong respon dan membentuk perilaku target pelanggan agar menimbulkan keinginan membeli suatu barang atau jasa yang ditawarkan. Jadi direct marketing merupakan pemasaran 
relasional yaitu pemasaran yang terfokus pada pengembangan, pemeliharan dan hubungan berkelanjutan antara pemasar dengan pelanggannya untuk mendapat respon langsung. Pemsaran langsung adalah tentang fokus, komunikasi yang ditargetkan dengan pelanggan strategis untuk mempromosikan pembelian barang atau jasa. Keunggulan pemasaran dalam bisnis merupakan hal terpenting dalam persaingan pasar saat ini untuk memperoleh kesuksesan dan kelangsungan hidup perusahaan (Thomas, 2007).

\section{Face to face selling}

Face to face selling merupakan bentuk dircet marketing yang dilakukan oleh pihak perusahaan melalui wiraniaga yang terpilih dengan cara presentasi langsung atau demonstrasi dalam melakukan penjualan produk serta memberikan pelayanan kepada pelanggan potensial secara langsung dengan tujuan mendapatkan respon pembelian (Blech, 2009). Face to face selling adalah komunikasi yang bersifat pribadi dan dua arah yang dilakukan oleh tenaga penjual (wiraniaga) dengan menyampaikan pesan secara langsung kepada pembeli, yang dimaksudkan untuk mempengaruhi konsumen untuk menciptakan pembelian. Oleh karena itu komunikasi secara persuasif sangat ditekankan pada face to face selling agar dapat menggugah konsumen untuk melakukan pembelian. Manfaat dari penjualan ini adalah meminimalisir modal biaya yang dikeluaran karena perusahaan dapat mengatur sendiri kapan dan dimana penjualan ingin dilakukan (Swaroopa Rani \& Swaroopa Rani Direct, 2016).

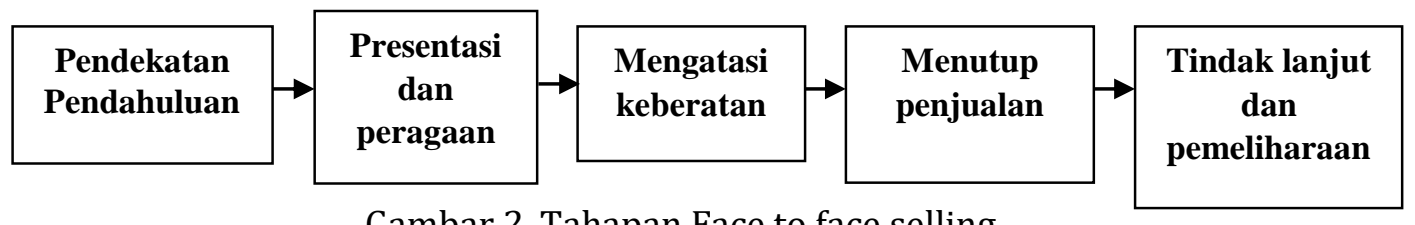

Gambar 2. Tahapan Face to face selling

\section{Online Marketing}

Online Marketing adalah kegiatan promosi atau penjualan melaui media sosial dengan memanfaatkan jaringan intenet dan gadget. Promosi dapat berupa informasi mengenai perusahaan, barang dan jasa yang ditawarkan. Selain itu calon pembeli juga dapat melakukan transaksi pembelian melalui pilihan menu yang disediakan perusahaan melalui media sosialnya (Blech, 2009).

Keberadaan web adalah objek utama dari online marketing yang mengarahkan pelanggan ke laman website milik perusahaan untuk melihat layanan, memesan hingga membeli produk. Tujuan dari online marketing adalah untuk mendapatkan interaksi tingkat tinggi dengan pelanggan untuk mempengaruhi tindakan mereka melakukan pembelian. Online marketing merupakan media iklan yang sangat menghemat biaya perusahaan karena tidak perlu membayar jasa iklan dan sewa tempat untuk menemui pelaggan potensial karena hal tersebut dapt dilakukan hanya dengan menggunakan mesin pencarian di internet. Tinginya tingkat persaingan online marketing mengharuskan perusahaan untuk dapat memahami dengan jelas kemauan pelanggan dengan memberikan informasi yang sesuai dengan strategi online marketing yang efisien dan tepat sasaran (Schwarzl \& Grabowska, 2015). Indikator penilaian pada online marketing dibagi menjadi kepercayaan, yaitu perusahaan harus dapat memberikan informasi sesuai dengan kenyataan yang akan ditampilkan di media sosial dengan tujuan untuk mendapatkan keyakinan konsumen. Indikator kedua adalah kemudahan, yaitu informasi yang disajikan perusahaan dan pemesan online harus mudah diakses oleh konsumen dan indikator ketiga adalah kualitas informasi yaitu informasi yang diberikan harus mempunyai kualitas yang baik agar tujuan yang ingin disampaikan kepada konsumen tepat sasaran. Pihak pemasar harus memiliki iklan yang bernilai untuk dapat menarik minat beli konsumen (Putri, 2017). 


\section{Keputusan Pembelian}

Keputusan pembelian adalah perilaku yang dtunjukkan pelanggan untuk mendapatkan barang dan jasa yang datawarkan melalui proses psikologis dengan mencari informasi, mengevaluasi barang atau jasa dan akhirnya melakukan pembelian barang atau jasa sesuai prasayarat harapan mereka untuk dikonsumsi yang setelah itu menimbulkan perilaku paska pembelian yang menentukan karakteristik pelanggan itu sendiri. Banyak Faktor yang mempengaruhi keputusan pembelian seperti faktor lingkungan dan faktor pribadi (Khuong \& Duyen, 2016). Menurut (Onigbinde Isaac Oladepo \& Abimbola, 2015) keputusan pembelian merupakan serangkaian pilihan yang dibuat konsumen sebelum melakukan pembelian. Wiraniaga atau pemasar harus memahami keinginan dan persepsi konsumen, sesuai dengan teori yang dikemukakan oleh (Philip Kotler, 2012) yaitu secara tidak sadar konsumen melewati beberapa langkah keputusan pembelian sebelum membeli suatu barang atau jasa yaitu mengetahui terlebih dahulu barang atau jasa yang ingin dibeli kemudian melakukan pencarian melalui sumber terdekat dan terpercaya seperti teman atau kerabat, wiraniaga, situs web atau publikasi lainnya. Setelah itu konsumen akan melakukan evaluasi terhadap barang atau jasa yang akan dibeli apakah sesuai atau tidak dengan karakterisitik yang dibutuhkan atau inginkan. Jika ketiga proses tersebut telah terlewati konsumen akan memutukan membeli pada tempat dan waktu yang tepat yang kemudia akan menimbulkan respon atau perilaku paska pembelian yang akan mempengaruhi keputusan pembelian selanjutnya dikemudian hari ( Sagala, Destriani, Putri, \& Kumar, 2014).

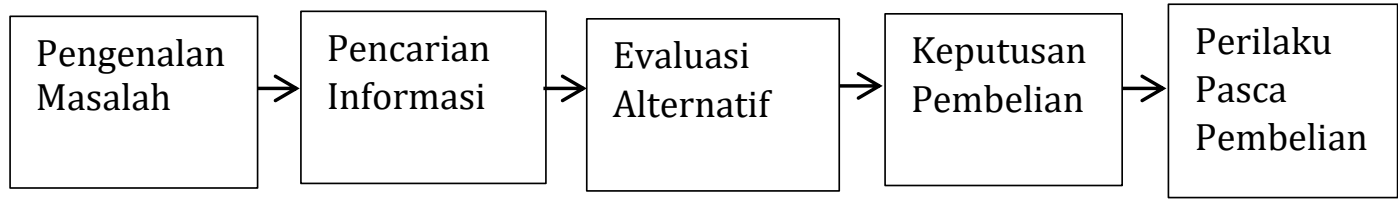

Gambar 3. Tahapan Keputusan Pembelian

Sumber : (Philip Kotler, 2012)

\section{Perumusan Hipotesis}

Hipotesis merupakan jawaban sementara dari permasalahan yang berkaitan dengan variabel yang diteliti dan akan dibuktikan berdasarkan teori- teori yang dikemukaan didukung dari hasil penelitian yang telah dilakukan. Artinya, hipotesis merupakan rumusan permasalahan yang masih harus dibuktikan kebenarannya secara empiris. Penyusunan hipotesis pada penelitian ini didasari oleh beberap dugaan bahwa direct marketing mempengaruhi keputusan pembelian. Menurut (Kotler, 2012) direct marketing adalah suatu cara pemasar dalam mengkomunikasikan barang atau jasa yang dijual untuk mendorong respon dan membentuk perilaku target pelanggan agar menimbulkan keinginan membeli suatu barang atau jasa yang ditawarkan. Direct marketing menurut (Tjiptono, 2008) adalah Pemasaran interaktif dengan menggunakan beberapa media dan dapat dilakukan disembarang lokasi untuk mendapatkan respon terukur dan transaksi antara tenaga penual dengan pelanggan saat penjualan dilakukan. Berdasarkan premis yang dikemukakan diatas maka hipotesis dalam penelitian ini adalah:

Hipotesis: Terdapat pengaruh direct marketing bersama-sama (simultan) yang terdiri dari face to face selling dan online marketing secara positif dan signifikan terhadap keputusan pembelian kopi arabika Malabar Mountain Coffee. Terdapat pengaruh direct marketing sendiri (parsial) yang terdiri dari face to face selling dan online marketing secara positif dan signifikan terhadap keputusan pembelian kopi arabika Malabar Mountain Coffee.

\section{METODE PENELITIAN}

Penelitian ini menganalisa tentang pengaruh direct marketing terhadap keputusan pembelian Kopi Arabika Malabar Mountain Coffee di PT Sinar Mayang Lestari. Objek yang menjadi penelitian ini adalah direct marketing yang terdiri dari Face to face selling dan online marketing yang menjadi 
variabel bebas atau variabel independent (X). Kemudian keputusan pembelian kopi arabika Malabar Mountain Coffee menjadi variabel terikat atau dependent (Y) yang mencangkup indikator pencarian informasi, evaluasi alternative, pengenalan masalah, keputusan pembelian dan perilaku paska pembelian. Berdasarkan jenis penelitiannya, metode yang digunakan adalah explanatory survey. Menurut (Sugiyono, 2013) metode explanatory survey merupakan metode penelitian yang digunakan untuk mengetahui kedudukan masing-masing variabel yang akan diteliti serta bagaimana hubungan antara satu variabel dengan variabel lainnya.

Populasi dalam penelitian ini adalah konsumen yang mengetahui dan membeli kopi arabika Malabar Mountain Coffee. Unsur populasi yang terpilih menjadi sampel dapat disebabkan karena kebetulan atau karena faktor lain yang sebelumnya sudah direncanakan oleh peneliti. Sampel adalah bagian dari populasi yang diteliti (Suharsimi, 2013) Metode pengambilan sample menggunakan metode purposive sampling, yaitu pengambilan sampel yang dipilih berdasarkan ketersediaan elemen yang sudah direncanakan dan dipertimbangkan dengan syarat tertentu oleh peneliti. Dalam penelitian ini sampel yang dipilih adalah responden yang pernah melakukan pembelian produk kopi arabika Malabar Mountain milik PT. Sinar Mayang Lestari minimal 1-3 kali dalam waktu 1 tahun terakhir melalui bentuk promosi direct marketing yaitu face to face selling dan online marketing.

\section{Analisis Deskriptif}

Menurut Sugiyono (2013), analisis deskriptif adalah menjelaskan atau menggambarkan data dari hasil temuan penelitian yang telah terkumpul sebagaimana adanya tanpa bermaksud membuat kesimpulan. Statistik deskriptif adalah bagian dari statistika yang mempelajari cara pengumpulan data dan penyajian data sehingga ciri responden dan variabel penelitian mudah dipahami, sedangkan penelitian kuantitatif digunakan untuk menguji hipotesis dengan menggunakan uji statistik

Analisis deskriptif digunakan dengan menyusun tabel frekuensi distribusi untuk mengatahui nilai (skor) variabel penelitian masuk dalam kategori sangat baik, baik, cukup, tidak baik dan sangat baik. Dalam menetapkan peringkat untuk setiap variabel penelitian dapat dilihat dari perbandingan antar skor aktual dengan skor ideal.

Jawaban responden pada instrument penelitian dapat diukur dengan menggunakan rumus sebagai berikut :

$$
\% \text { Skor Aktual }=\frac{\text { skor aktual }}{\text { skor ideal }} \times 100 \%
$$

\section{Keterangan :}

1. Skor aktual adalah jawaban seluruh responden atas kuesioner yang telah diajukan.

2. Skor idel adalah nilai tertinggi atau semua responden diasumsikan memilih jawaban dengan skor tertinggi

Adapun tabel kriteria presentase skor tanggapan terhadap skor total dapat dilihat pada tabel 1 dibawah yaitu :

Tabel 1. Kriteria Presentase Tanggapan Terhadap Skor Total.

\begin{tabular}{|c|c|c|}
\hline No. & \% Jumlah Skor & Kriteria \\
\hline 1. & $20.00-36.00$ & Tidak Baik \\
\hline 2. & $36.01-52.00$ & Kurang Baik \\
\hline 3. & $52.01-68.00$ & Cukup \\
\hline 4. & $68.01-84.00$ & Baik \\
\hline 5. & $84.01-100$ & Sangat Baik \\
\hline
\end{tabular}

Sumber : (Narimawati, 2007). 


\section{Analisis Regresi Linier Berganda}

Analisis kuantitatif adalah riset yang cara pengolahan datanya dihitung menggunakan analisis sistematis. Dalam penelitian ini menggunakan uji regresi linier berganda. Analisis linier berganda adalah hubungan secara linier antara dua atau lebih variabel indepeden (X1, X2, X3,...Xn) dengan variabel dependen (Y). Analisis regresi linier berganda digunakan untuk memeriksa kuatnya hubungan antara variabel bebas dengan variabel terikat. Menurut (Sugiyono, 2013) alat analisis ini untuk mengetahui arah hubungan antara variabel independen dengan variabel dependen apakah masing-masing variabel independen berhubungan positif atau negatif. Analisis regresi linier berganda dapat dilakukan apabila jumlah variabel independen minimal lebih dari satu atau lebih. Uji regresi linier berganda dapat dilihat dalam persamaan berikut:

$$
Y=a+b_{1} x_{1}+b_{2} x_{2}+b_{3} x_{3}+e
$$

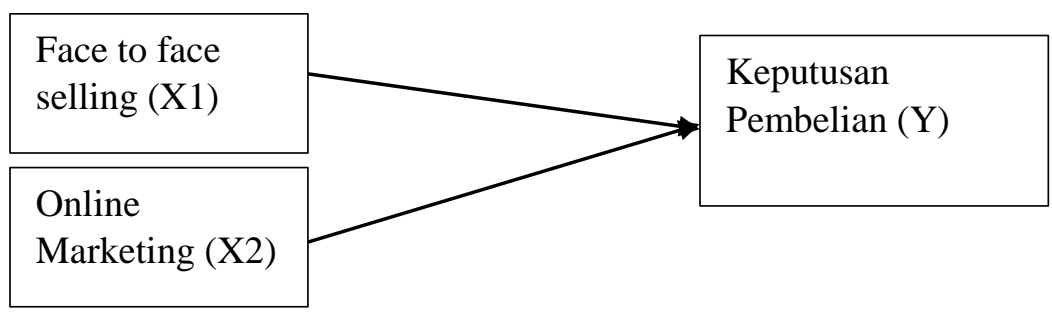

Gambar 4. Regresi Berganda

\section{Uji Hipotesis}

Uji F ini digunakan untuk mengetahui apakah variabel independent yaitu face to face selling (X1), dan online marketing (X2) bersama-sama berpengaruh secara signifikan terhadap variabel dependen yaitu keputusan pembelian (Y) pada tingkat kepercayaan $95 \%$ atau $\alpha=5 \%$. Hasil pengujian uji $\mathrm{F}$ dapat ditemui pada tabel ANOVA (Analysis of Variance) dari output SPSS versi 20.0 untuk menjawab hipotesis statistik yaitu Ho= variabel Direct Marketing tidak ada pengaruh signifikan secara simultan terhadap variabel Keputusan Pembelian, H1= variabel Direct Marketing berpengaruh signifikan secara simultan terhadap variabel Keputusan Pembelian Dengan kriteria $\mathrm{Ho}=$ ditolak dan Ha diterima, jika nilai signifikan ( $\mathrm{P}$ Value) $<0,05 . \mathrm{H1}=$ diterima dan Ha ditolak, jika nilai signifikan ( $\mathrm{P}$ Value) $>0,05$.

Uji ini t digunakan untuk mengetahui apakah dalam model regresi variabel independen yaitu face to face selling (X1), dan online marketing (X2) secara parsial berpengaruh signifikan terhadap variabel dependen yaitu keputusan pembelian (Y) pada tingkat kepercayaan 95\% atau $\alpha=5 \%$ menggunakan SPSS versi $20.0 \mathrm{H0}$ : Tidak ada pengaruh yang signifikan secara parsial antara face to face selling dengan keputusan pembelian. H1 : Ada pengaruh yang signifikan secara parsial antara face to face selling dengan keputusan pembelian. H0 : Tidak ada pengaruh yang signifikan secara parsial antara online marketing dengan keputusan pembelian. H1 : Ada pengaruh yang signifikan secara parsial antara online marketing dengan keputusan pembelian. Bila nilai signifikan (P Value) $<0,05$ maka (Ho) ditolak dan menerima alternative (H1) yang berarti ada pengaruh antara variabel bebas dan variabel terikat. Bila nilai signifikan (P Value) $>0,05$ maka (Ho) diterima dan menolak alternative (H1) yang berarti tidak ada pengaruh antara variabel bebas dan variabel terikat. 


\section{HASIL PEMBAHASAN}

Tabel 2. Pelaksanaan direct marketing PT. Sinar Mayang Lestari

\begin{tabular}{|c|c|}
\hline Strategi & kripsi Kegiatan \\
\hline $\begin{array}{l}\text { Face to face } \\
\text { selling }\end{array}$ & $\begin{array}{l}\text { Pihak PT. Sinar Mayang Lestari melakukan interaksi tatap muka langsung } \\
\text { dengan konsumen. } \\
\text { Pihak PT. Sinar Mayang Lesatri menjelaskan informasi mengenai produk } \\
\text { kopi Arabika Malabar Mountain. } \\
\text { Pihak PT. Sinar Mayang Lestari menawarkan produk kopi arabika } \\
\text { Malabar Mountain kepada konsumen } \\
\text { PT. Sinar Mayang Lestari rutin mengikuti kegiatan pameran kopi se-Jawa } \\
\text { Barat bahkan se-Indonesia sekaligus memberi kopi seduhan manual } \\
\text { brew dan espresso secara gratis sebagai cara untuk mengenalkan kopi } \\
\text { arabika Malabar Mountain Coffee kepada konsumen. } \\
\text { PT. Sinar Mayang Lestari mengadakan Kompetisi menyeduh kopi dengan } \\
\text { kolega seperti keluarga,mitra,sahabat dan juga para konsumen. }\end{array}$ \\
\hline Online Marketing & $\begin{array}{l}\text { PT. Sinar Mayang Lestari melakukan beberapa kegiatan pemasaran } \\
\text { dengan mempromosikan keadaan perusahaan melalui media sosial. } \\
\text { Media sosial yang digunakan adalah } \\
\text { (www.malabarmountaincoffee.com), } \\
\text { (www.instagram.com/malabarmountaincoffee), penjualan produk di } \\
\text { online shopping platform Tokopedia (kopi Malabar Mountain Coffee) dan } \\
\text { dapat melakukan interaksi dengan wiraniaga media sosial whatsapp. Jika } \\
\text { pelanggan tertarik setelah melihat malabar mountain Coffee melalui } \\
\text { media sosial tersebut, pelanggan dapat datang langsung ke perusahaan } \\
\text { atau coffee shop malabar mountain cafe di bogor. }\end{array}$ \\
\hline
\end{tabular}

\section{Tanggapan Konsumen PT. Sinar Mayang Lestari terhadap Face to face selling}

Tabel 3. Rekapitulasi Tanggapan Konsumen untuk Variabel Face to Face Selling.

\begin{tabular}{lcccc}
\hline Indikator & Skor Aktual & Skor Ideal & $\begin{array}{c}\text { Presentase } \\
\text { (\%) }\end{array}$ & Kriteria \\
\hline $\begin{array}{l}\text { Pendekatan } \\
\text { Pendahuluan }\end{array}$ & 1272 & 1500 & 84,8 & Sangat Baik \\
\hline $\begin{array}{l}\text { Presentasi } \\
\text { dan Peragaan }\end{array}$ & 881 & 1000 & 88,1 & Sangat Baik \\
\hline $\begin{array}{l}\text { Mengatasi } \\
\text { Keberatan }\end{array}$ & 825 & 1000 & 82,5 & Sangat Baik \\
\hline $\begin{array}{l}\text { Menutup } \\
\text { Penjualan }\end{array}$ & 864 & 1000 & 86,4 & Sangat Baik \\
\hline $\begin{array}{l}\text { Tindak Lanjut } \\
\text { dan } \\
\text { Pemeliharaan }\end{array}$ & 428 & 500 & 85,6 & Sangat Baik \\
\hline \multicolumn{1}{c}{ Jumlah } & $\mathbf{4 2 7 0}$ & $\mathbf{5 0 0 0}$ & $\mathbf{8 5 , 4}$ & Sangat Baik \\
\hline
\end{tabular}

Sumber: Data Primer yang telah diolah, 2018.

Berdasarkan perhitungan tabel 3, diatas dapat disimpulkan bahwa tanggapan konsumen terhadap kegiatan face to face selling dengan 6 indikator pertanyaan menghasilkan nilai sebesar $85.4 \%$. Hal ini menunjukkan bahwa tanggapan konsumen untuk kegiatan face to face selling yang dilakukan oleh 
wiraniaga PT. Sinar Mayang Lestari termasuk dalam kriteria sangat baik dengan indikator presentasi dan peragaan yang memiliki presentase nilai tertinggi yaitu sebesar $88,1 \%$.

Tanggapan Konsumen PT. Sinar Mayang Lestari terhadap Online Marketing

Tabel 4. Rekapitulasi Tanggapan Konsumen untuk Variabel Online Marketing

\begin{tabular}{lcccc}
\hline Indikator & Skor Aktual & Skor Ideal & Presentase (\%) & Kriteria \\
\hline Kepercayaan & 823 & 1000 & 82,3 & Baik \\
\hline Kemudahan & 766 & 1000 & 76,6 & Baik \\
\hline $\begin{array}{l}\text { Kualitas } \\
\text { Informasi }\end{array}$ & 1090 & 1500 & 72,6 & Baik \\
\hline Jumlah & $\mathbf{2 6 7 9}$ & $\mathbf{3 5 0 0}$ & $\mathbf{7 6 , 5}$ & Baik
\end{tabular}

Sumber : Data primer yang telah diolah, 2018.

Berdasarkan perhitungan pada tabel 4, maka dapat disimpulkan bahwa tanggapan konsumen terhadap kegiatan online marketing dengan 3 indikator pertanyaan menghasilkan nilai sebesar 76,5\%. Hal ini menunjukkan bahwa tanggapan konsumen untuk kegiatan online marketing yang dilakukan oleh wiraniaga PT. Sinar Mayang Lestari termasuk dalam kriteria baik dengan indikator Kepercayaan informasi dan kualitas produk yang ditampilkan di media sosial yang memiliki presentase nilai tertinggi yaitu sebesar $82,3 \%$. Namun skor keseluruhan online marketing lebih rendah dibandingkan face to face selling.

Tanggapan Konsumen PT. Sinar Mayang Lestari terhadap Keputusan Pembelian

Tabel 5. Rekapitulasi Tanggapan Konsumen untuk Variabel Keputusan Pembelian Kopi Arabika Malabar Mountain Coffee

\begin{tabular}{lcccc}
\hline \multicolumn{1}{c}{ Indikator } & $\begin{array}{c}\text { Skor } \\
\text { Aktual }\end{array}$ & $\begin{array}{c}\text { Skor } \\
\text { Ideal }\end{array}$ & $\begin{array}{c}\text { Presentase } \\
\mathbf{( \% )}\end{array}$ & Kriteria \\
\hline $\begin{array}{l}\text { Pengenalan } \\
\text { Masalah }\end{array}$ & 430 & 500 & 86,0 & Sangat Baik \\
\hline $\begin{array}{l}\text { Pencarian } \\
\text { Informasi }\end{array}$ & 424 & 500 & 84,8 & Sangat Baik \\
\hline $\begin{array}{l}\text { Evaluasi Alternatif } \\
\text { Keputusan } \\
\text { Pembelian }\end{array}$ & 823 & 1000 & 82,3 & Baik \\
\hline $\begin{array}{l}\text { Perilaku } \\
\text { Pembelian }\end{array}$ & 839 & 1000 & 83,9 & Baik \\
\hline \multicolumn{1}{c}{ Jumlah } & 885 & 1000 & 88,5 & Sangat Baik \\
\hline
\end{tabular}

Sumber : Data primer yang telah diolah, 2018.

Berdasarkan perhitungan tabel 5 diatas, dapat disimpulkan bahwa tanggapan konsumen terhadap keputusan pembelian Kopi Arabika Malabar Mountain Coffee dengan 5 indikator pertanyaan menghasilkan presentase nilai sebesar $85,0 \%$. Hal ini menunjukkan bahwa tanggapan responden untuk keputusan pembelian termasuk dalam kriteria sangat baik dengan indikator perilaku paska pembelian memberikan presentase nilai tertinggi yaitu sebesar $88,5 \%$.

\section{Pengaruh Direct Marketing terhadap keputusan pembelian Uji Regresi Linier Berganda}

Berdasarkan hipotesis dalam penelitian ini menggunakan jenis data yang dikumpulkan, maka analisis data yang digunakan dalam penelitian ini adalah analisis regresi linier berganda untuk mengetahui 
seberapa besar pengaruh direct marketing yang terdiri dari face to face selling dan online marketing terhadap keputusan pembelian Kopi Arabika Malabar Mountain Coffee.

\section{Tabel 6. Hasil Uji Regresi Linier Berganda} Coefficients

\begin{tabular}{llllll}
\hline Model & \multicolumn{2}{l}{$\begin{array}{l}\text { Unstandardized } \\
\text { Coefficients }\end{array}$} & $\begin{array}{l}\text { Standardized } \\
\text { Coefficients }\end{array}$ & $\mathrm{t}$ & sig \\
\hline & $\mathrm{B}$ & Std. Error & Beta & & \\
\hline constant & .118 & 4.446 & & .027 & .979 \\
Face to face selling & .850 & 0.79 & .739 & 10.784 & .000 \\
Online Marketing & .074 & .132 & .039 & .564 & .574 \\
\hline
\end{tabular}

Dependent Variable: Keputusan Pembelian Kopi Arabika Malabar Mountain Coffee (Y)

Sumber : Data diolah, 2018.

Tabel diatas Menunjukkan hasil t hitung didapatkan persamaan regresi berganda untuk pengaruh direct marketing terhadap keputusan pembelian. Bentuk persamaannya adalah :

$$
\begin{gathered}
Y=a+b_{1} x_{1}+b_{2} x_{2}+e \\
Y=0,118+0,850+0,074++4,446
\end{gathered}
$$

Hasil analisis menunjukkan nilai konstanta 0,118 artinya jika X1 dan X2 diabaikan maka tingkat keputusan pembelian adalah sebesar 0,118. Koefisien X1 memiliki nilai sebesar 0,850 berarti bahwa untuk setiap kenaikan satu satuan nilai face to face selling akan menaikkan keputusan pembelian sebesar 0,850. Koefisien X2 sebesar 0,074 menyatakan bahwa untuk setiap kenaikan satu satuan online marketing maka akan menaikkan nilai keputusan pembelian sebesar 0,074 . Uji $\mathrm{F}$ digunakan untuk mengetahui pengaruh keseluruhan variabel bebas secara bersama-sama (simultan) terhadap variabel terikat. Uji F dapat dilakukan dengan membandingkan F hitung dengan F tabel untuk menguji signifikansi dari analisis regresi.

Tabel 7. Hasil Uji Hipotesis ( Uji F ) ANOVA

\begin{tabular}{llllll}
\hline Model & Sum of Squares & df & Mean Square & F & Sig \\
\hline Regression & 1204.309 & 2 & 602.155 & 61.145 & $.000^{\mathrm{b}}$ \\
Residual & 955.251 & 97 & 9.848 & & \\
Total & 2159.560 & 99 & & & \\
\hline
\end{tabular}

Dependent Variabel : Keputusan Pembelian Kopi Arabika Malabar Mountain Coffee (Y) Predictors (Constant), Online Marketing (X2), Face to face selling (X2)

Sumber : Data diolah, 2018.

Berdasarkan tabel diatas diperoleh hasil $\mathrm{F}$ hitung sebesar 61,145 sedangkan $\mathrm{F}$ tabel dengan derajat kebebasan pada $\alpha(0,05)$ adalah sebesar 3,09 dengan demikian $\mathrm{F}$ hitung $(61,145)>\mathrm{F}$ tabel $(3,09)$ dengan nilai signifikansi $0,000<0.05$. Dari Hasil perhitungan menggunakan SPSS 20 dapat disimpulkan terdapat pengaruh secara simultan yang signifikan antara direct marketing yang terdiri dari face to face selling dan online marketing terhadap keputusan pembelian kopi arabika Malabar Mountain Coffee. Hal ini mengindikasikan bahwa apabila program direct marketing yang terdiri dari face to face selling dan online marketing dijalankan bersama-sama dengan baik akan mempengaruhi konsumen untuk membeli produk kopi arabika Malabar Mountain Coffee.

Uji t bertujuan untuk melihat pengaruh masing-masing variabel independen terhadap variabel dependen dan signifikan atau tidak. Pengujian ini dilakukan untuk mengetahui pengaruh variabel yang paling dominan dari keseluruhan variabel yang terdiri dari face to face selling (X1) dan online marketing (X2). Regresi sebuah variabel mempunyai pengaruh yang berarti terhadap perubahan nilai $\mathrm{Y}$ jika nilai t hitung lebih besar dari t tabel ( $\mathrm{t}$ hitung $>\mathrm{t}$ tabel). 
Berdasarkan perhitungan tabel 6 yang telah disajikan diatas secara parsial menunjukkan bahwa uji t terhadap variabel face to face selling, menghasilkan nilai t hitung sebesar $=10,784>$ nilai t tabel $=1,984$ dan hasil signifikansi yang diperoleh sebesar $=0,000<0,05$, maka secara parsial face to face selling berpengaruh positif dan signifikan terhadap Keputusan Pembelian kopi arabika Malabar Mountain Coffee.

Penjualan tatap muka atau face to face selling memiliki keunggulan yaitu wiraniaga dapat menyampaikan informasi tentang karakteristik produk yang dijual secara lebih kompleks dibandingkan dengan media iklan yang lain seperti media elektronik ataupun media cetak, selain itu wiraniaga juga dapat mendemonstrasikan produk yang dijual secara langsung kepada konsumen potensial untuk memperoleh perhatian serta umpan balik konsumen itu sendiri. Hal tersebut sesuai dengan penjualan face to face selling yang dilakukan oleh wiraniaga PT. Sinar Mayang Lestari, dimana wiraniaga menjelaskan langsung ke konsumen tentang karakteristik produk yang dijual serta mendemonstrasikan pembuatan kopi kepada konsumen potensial sehingga menimbulkan ketertarikan konsumen untuk membeli produk yang ditawarkan.

Uji t terhadap variabel online marketing, menunjukkan nilai t hitung sebesar $=0,546<$ nilai t tabel $=1,984$ dan hasil signifikansi yang diperoleh sebesar $=0,574>0,05$, maka secara parsial online marketing tidak berpengaruh signifikan terhadap keputusan pembelian kopi Arabika Malabar Mountain Coffee. Hal ini disebabkan karena pengelolaan media sosial PT. Sinar Mayang Lestari masih dinilai belum optimal, dimana perusahaan masih belum menampilkan informasi dengan lengkap pada media sosial instagram, dan website Malabar Mountain Coffee sehingga konsumen tidak mengetahui informasi secara lengkap mengenai produk yang dijual seperti dari segi bentuk produk yang dijual, varian menu yang ditawarkan, dan harga produknya. Selain itu, PT. Sinar Mayang Lestari jarang memperbarui laman media sosialnya sehingga konsumen tidak mengetahui kabar terbaru mengenai perusahaan yang menyebabkan menurunnya antusias konsumen terhadap produk yang dijual. Hal tersebut sesuai dengan model periklanan Model Lavidge Gary Steiner (Kasali, 2007) yaitu, komunikasi yang diawali dengan kesadaran mengenalkan produk melalui pesan sederhana secara terus menerus dengan mengulang nama produk akan mendorong target pasar (konsumen) mempunyai pengetahuan yang lebih banyak tentang produk yang dijual dengan cara menyampaikan informasi tentang produk sehingga konsumen akan tertarik untuk membeli namun sebaliknya apabila komunikasi jarang dilakukan konsumen akan beralih ke produk lain yang lebih sering menawarkan produknya secara terus menerus (Kasali, 2007). PT Sinar Mayang Lestari harus memperbaiki kinerja pengelolaan media sosialnya agar dapat menarik minat beli konsumen terhadap produk yang dijualnya. Menurut (Kotler, 2012) apabila sistem belanja melalui media online masih dalam masa pertumbuhan dan belum menjadi sangat sukses seperti yang diharapkan, disebabkan karena kurangnya jumlah keangotaan dan keterampilan pengelolaan komputer.

Model Summary

\begin{tabular}{|l|l|l|l|l|}
\hline Model & $\mathrm{R}$ & R Square & Adjusted R Square & Std. Error of the Estimate \\
\hline 1 & $.747 \mathrm{a}$ & .558 & .549 & 3.13814 \\
\hline
\end{tabular}

Sumber : Data diolah, 2018

Berdasarkan model summary uji regresi linier berganda pada tabel diatas diperoleh nilai koefisien determinasi $\left(\mathrm{R}^{2}\right)$ sebesar 0,558 atau 55,8\%. Hal ini menunjukkan bahwa direct marketing memiliki pengaruh terhadap keputusan pembelian Kopi Arabika Malabar Mountain Coffee dengan kontribusi sebesar 55,8\%, sedangkan sisanya sebesar 44,2\% dipengaruhi oleh faktor-faktor yang tidak diteliti dalam penelitian ini.

Hasil Penelitian ini menunjukkan bahwa hipotesis diterima yaitu direct marketing bersama-sama (simultan) berpengaruh positif terhadap keputusan pembelian sekligus memperkuat penelitiansebelumnya yang dilakukan oleh (Purnama, 2016) yang menyatakan bahwa direct 
marketing mempengaruhi keputusan pembelian secara positif dan signifikan. Namun hipotesis kedua diotal karena secara sendiri (parsial) online marketing tidak berpengaruh signifikan terhadap keputusan pembelian Kopi Arabika Malabar Mountain Coffee.

\section{KESIMPULAN}

Pelaksanaan direct marketing yang telah dilaksanakan PT. Sinar Mayang Lestari berada pada kategori penilaian tinggi. Hal ini menunjukkan bahwa pelaksanaan direct marketing sudah memenuhi keinginan konsumen PT. Sinar Mayang Lestari. Face to face selling berada pada kriteria sangat baik, online marketing berada pada kriteria baik dan keputusan pembelian berada pada kriteria sangat baik. Direct marketing yang terdiri dari face to face selling dan online marketing bersama - sama memiliki kontribusi dan berpengaruh signifikan terhadap keputusan pembelian kopi arabika Malabar Mountain Coffee, yang artinya bahwa semakin baik direct marketing maka akan semakin mempengaruhi keputusan pembelian kopi arabika Malabar Mountain Coffee. Namun secara parsial online marketing tidak mempengaruhi keputusan pembelian kopi arabika Malabar Mountain Coffee karena penilaian konsumen terhadap indikator kualitas informasi rendah yaitu perusahaan jarang memperbarui laman website dan media sosial serta tidak lengkap menampilkan informasi di website dan media sosial. Berdasarkan kesimpulan dari hasil penelitian, maka penulis memberikan saran bagi perusahaan yaitu PT. Sinar Mayang Lestari dalam melaksanakan program direct marketing hendaknya mengoptimalkan semua bentuk direct marketing yang dilakukan sehingga akan terjadi keseimbangan antara semua bentuk direct marketing sehingga pemasaran kopi arabika Malabar Mountain Coffee dapat bersaing dengan perusahaan lain dalam menarik minat beli konsumen untuk menciptakan keputusan pembelian. Mempertahankan kinerja dan kemampuan wiraniaga dalam menjelaskan atau menawarkan produk ke konsumen secara langsung serta lebih aktif dalam mengikuti exhibition coffe dan kegiatan education coffee agar banyak konsumen lebih mengetahui produk Malabar Mountain Coffee.

Meningkatkan kinerja dan kemampuan wiraniaga dalam pemasaran online (online marketing) dengan melengkapi informasi yang ditampilkan dimedia sosial yaitu menambahkan informasi mengenai spesifikasi produk dan varian produk yang dijual, komposisi dan kandungan produk yang dijual serta harga produk yang dijual. Selain itu, wiraniaga juga harus selalu/sering memperbarui laman media sosialnya agar memunculkan minat beli konsumen karena selalu melihat update informasi mengenai produk kopi arabika PT. Sinar Mayang Lestari.

\section{IMPLIKASI}

Penelitian ini merupakan penelitian empiris yang hasilnya dapat dimanfaatkan dan sebagai bahan masukan bagi PT. Sinar Mayang Lestari dengan mengoptimalkan direct marketing untuk dapat mempengaruhi pelanggan memutuskan membeli Kopi Arabika Malabar Mountain Coffee.

\section{KETERBATASAN PENELITIAN}

Penelitian ini hanya berfokus kepada 2 bentuk strategi direct marketing yaitu face to face selling dan Online marketing terhadap keputusan pembelian, untuk penelitian selanjutnya disarankan agar lebih mengeksploitasi lagi bentuk strategi direct marketing seperti telemarketing, direct mail, Direct Response Television Marketing, katalog marketing, dan endorsement marketing terhadap keputusan pembelian.

\section{DAFTAR PUSTAKA}

Blech, G. E. and B. M. A. (2009). Advertising and Promotion : An Integrated Marketing Communication Perspective (8th ed.). New York: McGraw - Hill.

Indonesia, B., Sagala, C., Destriani, M., Putri, U. K., \& Kumar, S. (2014). Influence of Promotional Mix and Price on Customer Buying Decision toward Fast Food sector: A survey on University Students in Jabodetabek ( Jakarta , Bogor , 4(1), 1-7. 
Kasali, R. (2007). Manajemen Periklanan. Jakarta: Pustaka Utama Grafiti.

Khuong, M. N., \& Duyen, H. T. M. (2016). Personal Factors Affecting Consumer Purchase Decision towards Men Skin Care Products - A Study in Ho Chi Minh City, Vietnam. International Journal of Trade, Economics and Finance, 7(2), 44-50. https://doi.org/10.18178/ijtef.2016.7.2.497

Narimawati, U. (2007). Metodologi Penelitian Kualitatif dan Kuantitatif. Teori dan Aplikasi. Jakarta: Agung Media.

Onigbinde Isaac Oladepo, \& Abimbola, O. S. (2015). The Influence Of Brand Image And Promotional Mix On Consumer Buying Decision-A Study Of Beverage Consumers In Lagos State, Nigeria. British Journal Of Marketing Studies, 3(4), 97-109.

Philip Kotler, G. A. (2012). Prinsip-prinsip Pemasaran. (Erlangga, Ed.) (13th ed.). Jakarta.

Purnama, R. (2016). PENGARUH DIRECT MARKETING TERHADAP KEPUTUSAN PEMBELIAN DI, (1), 973-982.

Putri, F. H. (2017). Analisis Pengaruh Online Marketing Terhadap Keputusan Pembelian (Studi Kasus Hotel di Bogor). Sarjana, Program Jenis, Alih Manajemen, Departemen Ekonomi, Fakultas Manajemen, D A N.

Rodriguez, M., Dixon, A. L., \& Peltier, J. W. (2014). A review of the interactive marketing literature in the context of personal selling and sales management: A research agenda. Journal of Research in Interactive Marketing, 8(4), 294-308. https://doi.org/10.1108/JRIM-06-2014-0035

Schwarzl, S., \& Grabowska, M. (2015). Online marketing strategies: the future is here. JOURNAL OF INTERNATIONAL STUDIES. https://doi.org/10.14254/2071-8330.2015/8-2/16

Sugiyono. (2013). Metode Penelitian Kuantitatif, Kualitatif dan R\&D. Jakarta: Alfabet.

Suharsimi, A. (2013). Prosedur Penelitian : Suatu Pendekatan Praktik. Jakarta: Rineka Cipta.

Swaroopa Rani, G. N., \& Swaroopa Rani Direct, G. N. (2016). Direct selling and its benefits to the market place. Int. Res. J. of Science \& Engineering, 4(2), 57-64. Retrieved from www.irjse.in

Thomas, A. R. (2007). The end of mass marketing: Or, why all successful marketing is now direct marketing. Direct Marketing: An International Journal, 1(1), 6-16. https://doi.org/10.1108/17505930710734107

Tjiptono, F. (2008). Strategi Pemasaran. Yogyakarta: Andi.

Ukaj, F., \& Prof, A. (2016). Direct Marketing: An Imperative In Building Effective Comunication In Hospitality Enterprises. European Scientific Journal, 12(10), 240-248. https://doi.org/10.19044/esj.2016.v12n10p240 